\title{
Use of serial exercise tests to assess the efficacy and duration of action of drugs for asthma
}

\author{
M. S I L VER MA N,P. KON I G, a d S. G O D F R E Y \\ With the technical assistance of Tina Andrea \\ Department of Paediatrics, Cardiothoracic Institute and Brompton Hospital, Fulham Road, London SW3
}

\begin{abstract}
Silverman, M., Konig, P., and Godfrey, S. (1973). Thorax, 28, 574-578. Use of serial exercise tests to assess the efficacy and duration of action of drugs for asthma. A technique for studying the efficacy and duration of action of drugs used in asthma by means of exercise tests is described. The patient runs for six minutes every two hours, four times a day, on a treadmill at a constant speed and slope. The test drug or its placebo is given immediately before the first test of the day, and their effects on the exercise-induced asthma are compared. This enables the immediate protection and duration of action of the test drug to be measured. No change in the severity of post-exercise asthma was found when serial tests were performed during one day after administration of a placebo.

In a selected group of 14 children studied with disodium cromoglycate, three patterns were seen. In five patients the drug afforded prolonged benefit, in five others the protection was very short-lived, and in four patients it did not seem to be better than the placebo.

The use of the tests is also illustrated with respect to bronchodilator drugs.
\end{abstract}

The clinical evaluation of drugs in asthma can be time-consuming and inaccurate, and recent studies have shown that great care is needed to obtain objective evidence of efficacy (Silverman, Connolly, Balfour-Lynn, and Godfrey, 1972). No satisfactory method exists whereby it is possible to predict the value of a drug for an individual asthmatic patient.

Many workers have attempted to predict the extent and duration of action of drugs in asthmatic patients by means of serial measurements of lung function after administration of drugs to patients at rest (Tattersfield and McNicol, 1969 ; Hambleton and Shinebourne, 1970 ; Kamburoff and Prime, 1970 ; Connolly, 1971). The interpretation of these studies is rendered difficult because large spontaneous variations in airways resistance are known to occur in asthmatic patients (Lewinsohn, Capel, and Smart, 1960; Aepli, 1968) and because the effect of a drug on the airways resistance of resting patients may bear little relation to its value in preventing acute attacks of asthma (Sly, Heimlick, Busser, and Strick, 1967).

Exercise by running has been shown to provoke a brief attack of asthma in the majority of asthmatic children (Jones, 1966; Silverman and

1Requests for reprints should be addressed to Dr. S. Godfrey, Department of Child Health, Hammersmith Hospital, Du Cane Road, London W12
Anderson, 1972) and to be a useful model for the study of the efficacy of drugs in groups of sub- $\frac{1}{3}$ jects (Jones, Wharton, and Buston, 1963) and in individual patients (Connolly and Godfrey, 1970) It has been shown by Blackhall and Jones (1970) that exercise-induced asthma of children who responded well clinically to disodium cromoglycatex was better suppressed by the drug than thes exercise-induced asthma of poor responders 3 Recently, a significant degree of correlation waş demonstrated between the value of disodium cromoglycate in preventing attacks of asthmao induced by treadmill exercise in the laboratory and the year long clinical value of the druge (Silverman et al., 1972). The correlation was however, imperfect and it was realized that the duration of action of a drug might be clinically more important than its immediate effectiveness The technique of serial exercise testing described in this paper was therefore developed.

The technique will be illustrated mainly with reference to the drug disodium cromoglycate, buf? its application to the assessment of other drugs will be mentioned.

\section{PATIENTS AND METHODS}

All patients included in this study were children with asthma as defined by Scadding (1966), and were attending the Children's Asthma Clinic at Bromptop 
Hospital. All were shown in a preliminary test to develop exercise-induced asthma.

Exercise tests were carried out on a treadmill (Quinton) according to the method of Connolly and Godfrey (1970). Changes in airways obstruction were recorded by measurement of peak expiratory flow rate (PEFR) using a Wright peak flow meter (Airmed). Children ran for 6 minutes without pause at 3.0-3.5 m.p.h. on a $10^{\circ}$ slope. PEFR was measured before, during, and after exercise. Four tests were performed during the course of each day at 2-hourly intervals, the first at 10.00 a.m.

The drug under investigation was given immediately before the first test of the day. Either disodium cromoglycate (disodium cromoglycate, 20 $\mathrm{mg}$, +lactose, $20 \mathrm{mg}$ ) or a dummy capsule (lactose, $35 \mathrm{mg}$, + sodium sulphate, $5 \mathrm{mg}$ ) identical in appearance and flavour was given through a Spinhaler, the order of administration being varied. Other drugs given by aerosol, by mouth or by other routes, together with suitable dummy preparations, were tested in like manner.

Each drug or dummy was administered only once, before the first morning exercise test, and no other drugs were permitted during test days until the series had been completed. Each subject thus completed two test days of four runs. Both sets of tests were completed within one week.

For each exercise test the initial PEFR (as a percentage of the predicted value from Godfrey,
Kamburoff, and Nairn (1970)), and the maximum fall in PEFR after exercise (as a percentage of the initial PEFR) were recorded. All comparisons between tests were made by means of $t$ tests for paired values.

\section{RESULTS ${ }^{1}$}

For the whole group during the tests with disodium cromoglycate, as for each individual patient, the PEFR before exercise varied little between successive exercise tests or between the disodium cromoglycate and placebo test series (Figs 1a, b, c). During each test in the placebo series all subjects developed a fall in PEFR after exercise of more than $15 \%$, which is greater than 2 SD above the mean value for normal children (Silverman and Anderson, 1972). Moreover, during the placebo series, the mean fall in PEFR did not vary significantly between the four exercise tests of the day (Figs $1 a, b, c)$.

After administration of disodium cromoglycate there was initially a significant diminution in the mean severity of exercise-induced asthma in the whole group of 14 children studied $(P<0.01)$. The effect diminished progressively so that the mean difference between control and drug studies was just significant at 2 hours $(P<0.05)$ but not

1 Individual data will be supplied on request.

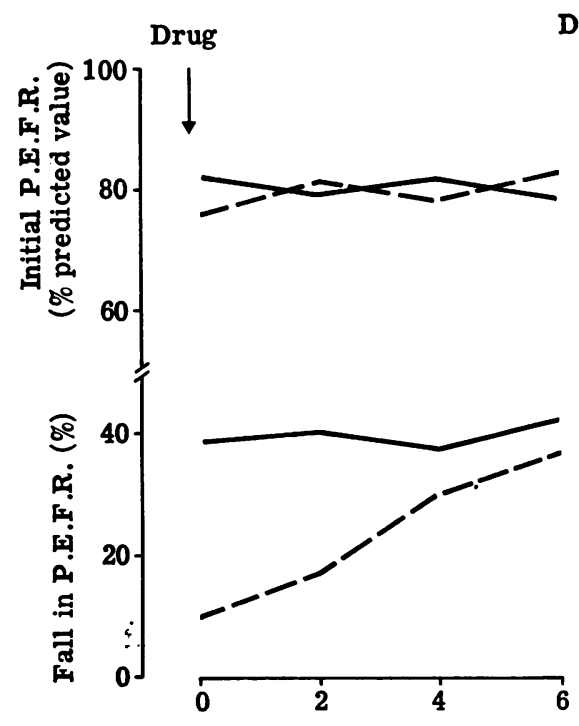

(a)

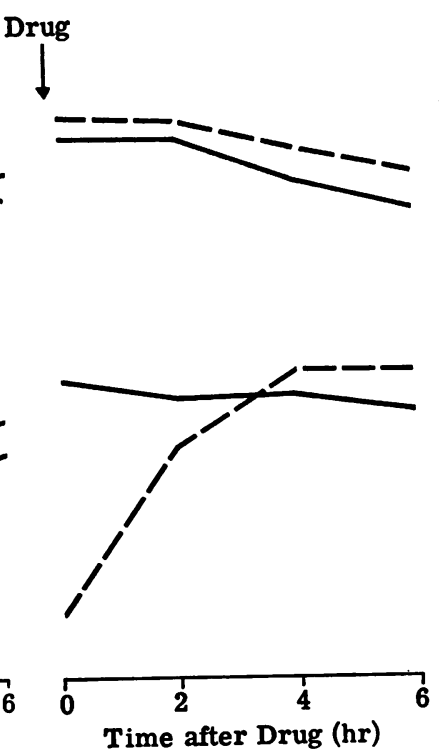

(b)
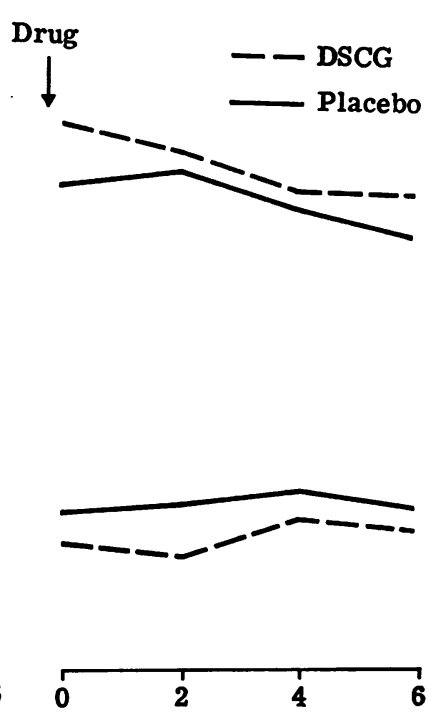

(c)

FIG. 1. Protection from exercise-induced asthma by disodium cromoglycate (DSCG) in 14 patients. The exercise tests were repeated every two hours throughout the day, but the drug or placebo was given only before the first test. There was no significant change in the initial peak flow rate in any test or in the fall in peak flow rate throughout the day after placebo. Three types of response were recognized: five patients were well protected (Fig. 1a), five for a short time only (Fig. 1b), and four not at all. 
statistically significant at 4 or 6 hours after administration. The patterns of response of the patients were divided arbitrarily into three groups. In five patients the drugs appeared to exert a prolonged beneficial effect (Fig. 1a); five patients derived only brief benefit (Fig. 1b), while in the remaining four, patients the drug appeared to have no useful effect (Fig. 1c).

The duration of protection can be quantified by noting the time during which the post-exercise bronchoconstriction after drug premedication is less than $50 \%$ of that after placebo premedication. This $50 \%$ protection lasted 2.4 hours in the group with prolonged response (Fig. 1a), 1.0 hour
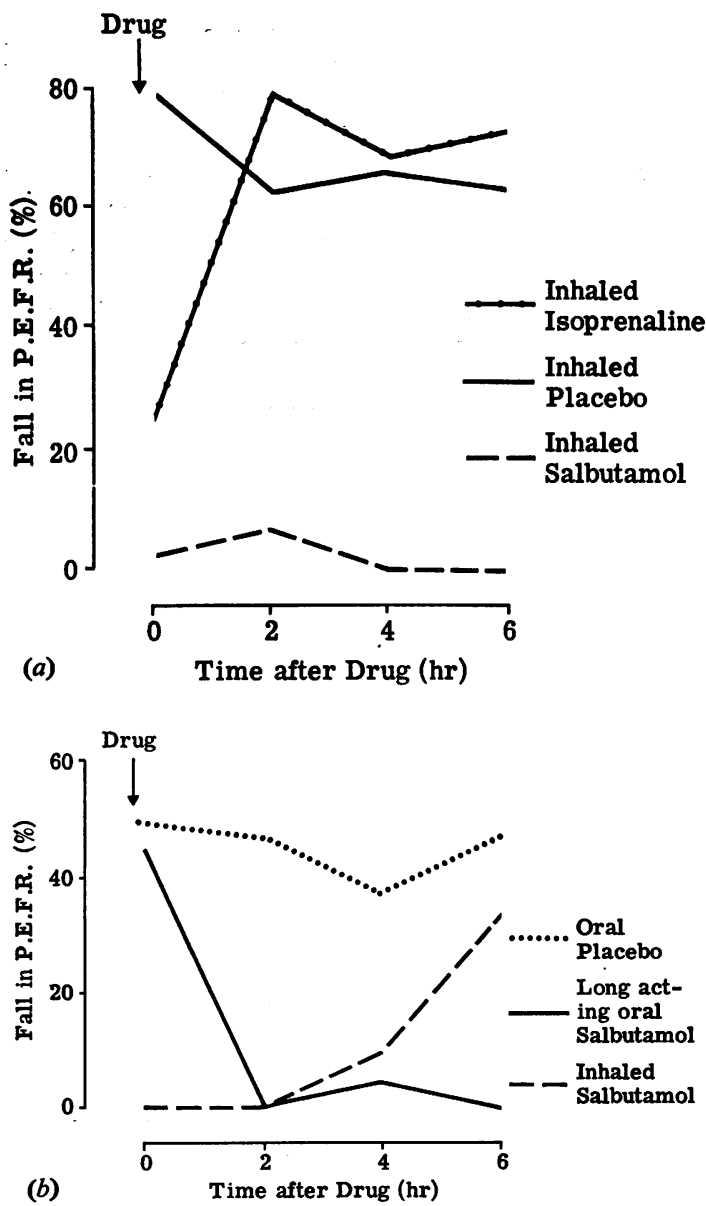

FIG. 2. The protection from exercise-induced asthma afforded by different bronchodilators is shown. Inhaled isoprenaline was much shorter acting than inhaled salbutamol (Fig. 2a). Oral long-acting salbutamol had no action at first because of the need for absorption but subsequently gave prolonged protection (Fig. 2b). in the group with brief benefit (Fig. 1b), and $\frac{\overline{ }}{5}$

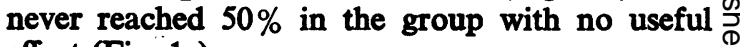
effect (Fig. 1c).

On open assessment by an independent observer, four out of five patients in the "prolonged $\vec{\circ}$ benefit' group were helped clinically by treatment with disodium cromoglycate, whereas only $\vec{\omega}$ three out of nine of the remainder of the patients were similarly helped clinically. The difference $\vec{x}$ between these two groups does not reach statisti- i cal significance.

As an illustration of the application of the $r$ serial exercise-test technique to the assessment of other drugs, Fig. 2a shows a comparison between the brief effect of inhaled isoprenaline and the $\vec{P}$ prolonged effect of inhaled salbutamol in one $\mathbb{D}$ patient. A comparison between inhaled sal- $\frac{\vec{D}}{\mathbb{D}}$ butamol and an oral slow-release preparation of $\frac{1}{3}$ salbutamol in another patient is shown in Figure $\mathbb{\Phi}$ $2 b$. The oral preparation had no immediate effect but gave lasting protection against exercise-in- $\vec{\varphi}$ duced asthma for between 2 and 6 hours after $\omega$ administration.

\section{DISCUSSION}

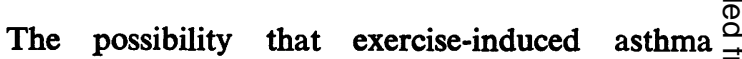
might provide a useful model for the assessment $\overrightarrow{0}$ of the efficacy of drugs in asthmatic children was suggested by Connolly and Godfrey (1970) and Blackhall and Jones (1970). Their prediction has recently been partially borne out during a long- $\vec{\partial}$ term clinical trial of disodium cromoglycate (Silverman et al., 1972), but the correlation $\times$ between laboratory tests and the long-term clinical 3 response was imperfect. For example, one patient $\bar{\delta}$ appeared at first to respond well to disodium $\frac{3}{3}$ cromoglycate administered prior to a single 0 exercise test but had a very poor long-term clinical response to the drug. Serial testing pro- $-\frac{D}{0}$ vided a possible explanation for the discrepancy, showing that the effect of the drug was of the $\tilde{N}$ transient type shown in Figure 1b. Likewise, $N$ Blackhall and Jones (1970) might have missed some important differences by waiting 30 minutes $\omega$ after giving the drug before starting exercise.

The present study has shown that serial testing $\stackrel{\circ}{ }$ can provide information concerning the duration $\cong$ of action of a drug as well as its potency. For a group of asthmatic children, the mean duration of $\overline{0}$ action of disodium cromoglycate would appear $\stackrel{\vec{D}}{\mathbb{D}}$ to be about 4 hours though its effect wanes pro- $\frac{?}{\mathbb{D}}$ gressively throughout this period. In individual $\cong$ patients some effect was seen from the drug for $\overline{2}$ up to 6 hours. The technique can be applied in the $\delta$ 
investigation of other drugs, as illustrated in Figure 2.

The prediction of the efficacy of drugs from the duration and degree of improvement of the FEV $_{1}$ or PEFR of patients at rest suffers from the disadvantage that spontaneous variations in the level of airways obstruction in asthmatic subjects from hour to hour are large (Lewinsohn et al., 1960 ; Aepli, 1968). On the other hand, the indices of exercise-induced asthma are highly reproducible over such intervals (Silverman and Anderson, 1972) and do not alter significantly with repetition during the day (Fig. 1). Another drawback at rest is that the effect of a drug on the level of airways resistance may be quite independent of its efficacy in diminishing or preventing attacks of asthma. Disodium cromoglycate, for instance, had no significant effect on the level of airways obstruction of asthmatics at rest whereas its value in diminishing the severity of asthma was clear (Fig. 1). In contrast, while atropine administered intravenously to asthmatic children produced a significant rise in PEFR, it had no significant effect on the severity of exerciseinduced asthma (Sly et al., 1967 ; Silverman, 1972) and has little place in the management of asthma.

Exercise testing is a form of challenge procedure which reproduces a symptom of importance in the daily life of many asthmatic children and which does not involve the administration of pharmacological agents such as histamine or methylcholine. The reproducibility of the treadmill running test, as described in this paper, is high in comparison with methylcholine challenge tests or with exercise tests employing other forms of exercise (Silverman and Anderson, 1972). Furthermore, unlike antigen challenge, exercise can induce asthma in non-atopic as well as in atopic subjects (Silverman and Turner-Warwick, 1972).

It has been suggested from the study of McNeill, Nairn, Millar, and Ingram (1966) that repeated testing on the same day causes less exerciseinduced asthma. The subject whose data they presented ran every 45 minutes. We have shown in substantial numbers of asthmatic children that, with a rest of 2 hours between tests, there is no significant change in response to repeated exercise (Fig. 1 and Silverman and Anderson, 1972).

There are certain limitations to the use of the exercise test technique. Not all asthmatic children develop exercise-induced asthma at the time of the study (Silverman and Anderson, 1972), many demonstrate a marked response to placebo (Silverman, 1972), and some have an erratic response to serial tests throughout the day (Silverman, 1972). These observations emphasize the need for a standardized form of exercise (Silverman and Anderson, 1972) employing running rather than cycling or walking (Silverman and Anderson, 1972; Anderson, Connolly, and Godfrey, 1971) and with adequate control data using a placebo. A further word of caution is also needed before extrapolating from exercise protection to clinical protection. Our continuing observations suggest that the correlation between these two aspects of asthma is not very good, and perhaps this is hardly surprising when one considers that corticosteroids can produce clinical benefit but have little effect on exercise-induced asthma.

Our technique can provide useful information on the duration of action of drugs with respect to exercise-induced asthma, and since $98 \%$ of children attending our asthma clinic have this symptom, it is of some therapeutic importance. Its wider significance remains to be determined.

This work was supported in part by the Medical Research Council and Fisons Pharmaceuticals.

\section{REFERENCES}

Aepli, R. (1968). Le rythme journalier de la résistance bronchique chez l'asthmatique. Respiration, 25, 405.

Anderson, S. D., Connolly, N. M., and Godfrey, S. (1971). Comparison of bronchoconstriction induced by cycling and running. Thorax, 26, 396.

Blackhall, M., and Jones, R. S. (1970). Effect of Intal on post-exercise bronchoconstriction in asthma. In: Disodium Cromoglycate in Allergic Airways Disease, edited by J. Pepys and A. W. Frankland, p. 63. Butterworth, London.

Connolly, N. M. (1971). Dosage of oral salbutamol in asthmatic children. Archives of Diseases in Childhood, 46, 869.

- , and Godfrey, S. (1970). Assessment of the child with asthma. Journal of Asthma Research, 8, 31.

Godfrey, S., Kamburoff, P. L., and Nairn, J. R. (1970). Spirometry, lung volumes and airway resistance in normal children aged 5 to 18 years. British Journal of Diseases of the Chest, 64, 15.

Hambleton, G., and Shinebourne, E. A. (1970). Evaluation of the effects of isoprenaline and salbutamol aerosols on airways obstruction and pulse rates of children with asthma. Archives of Diseases in Childhood, 45, 766.

Jones, R. S. (1966). Assessment of respiratory function in the asthmatic child. British Medical Journal, 2, 972.

Wharton, M. J., and Buston, M. H. (1963). The place of physical exercise and bronchodilator drugs in the assessment of the asthmatic child. Archives of Diseases in Childhood, 38, 539.

Kamburoff, P. L., and Prime, F. J. (1970). Oral and inhaled salbutamol as a bronchodilator. British Journal of Diseases of the Chest, 64, 46.

Lewinsohn, H. C., Capel, L. H., and Smart, J. (1960). Changes in forced expiratory volumes throughout the day. British Medical Journal, 1, 462. 
McNeill, R. S., Nairn, J. R., Millar, J. S., and Ingram, C. G. (1966). Exercise-induced asthma. Quarterly Journal of Medicine, 35, 55.

Scadding, J. G. (1966). Lancet, 1, 701.

Silverman, M. (1972). Exercise studies on asthmatic children. M.D. thesis, University of Cambridge.

- , and Anderson, S. D. (1972). The standardization of exercise tests in asthmatic children. Archives of Diseases in Childhood, 47, 882.

Connolly, N. M., Balfour-Lynn, L., and Godfrey, S. (1972). A long-term trial of disodium cromoglycate and isoprenaline in children with asthma. British Medical Journal, 3, 378.
- and Turner-Warwick, M. (1972). Exercise induced asthma: response to disodium cromoglycate in skin-test positive and skin-test negative subjects. Clinical Allergy, 2, 137.

Sly, R. M., Heimlick, E. M., Busser, R. J., and Strick, L. (1967). Exercise-induced bronchospasm: Effect of adrenergic or cholinergic blockade. Journal of Allergy, 40, 93.

Tattersfield, A. E., and McNicol, M. W. (1969). Salbutamol and isoproterenol. A double-blind trial to compare bronchodilator and cardiovascular activity. New England Journal of Medicine, 281, 1323. 